\title{
Perioperative Outcomes of Repeated Open Surgery on the Thoracic Aorta
}

\author{
Hunbo Shim, MD, Chang Seok Jeon, MD, Pyo Won Park, MD, Wook Sung Kim, MD, Young Tak Lee, MD, \\ Dong Seop Jeong, MD, Yang-hyun Cho, MD, Kiick Sung, MD \\ Department of Thoracic and Cardiovascular Surgery, Samsung Medical Center, Sungkyunkwan University School of Medicine, \\ Seoul, Korea
}

\section{ABSTRACT}

Background: Repeated thoracic aorta repair is increasingly common. With the increase in hybrid procedures, determination of the best treatment strategy requires evaluation of the clinical outcomes of classic open surgery.

Methods: We retrospectively reviewed 119 patients (84 men and 35 women, aged $51.0 \pm 16.7$ years) with a history of open repair involving the thoracic aorta above the diaphragm. The patients underwent an average of $1.3 \pm 0.8$ surgeries (range: 1-8) on the thoracic aorta before the final operation. Clinical outcomes were evaluated on the basis of the need for emergency surgery, indications for surgery, pathologic causes, and other operative variables.

Results: Hospital mortality was $6.7 \%(n=8)$. Postoperative bleeding occurred in $16 \%(\mathrm{n}=19)$. On multivariable analysis, emergency surgery (odds ratio [OR], 19.005; $P=.003 ; 95 \%$ confidence interval [CI], 2.710-133.305) and cardiopulmonary bypass $(\mathrm{CPB})$ time (OR, 1.562 per 30 minutes; $P=.007$; $95 \%$ CI, 1.126-2.165) were predictors of hospital death. Emergency surgery (OR, 4.105; $P=.029$; 95\% CI, 1.157$14.567)$ and $\mathrm{CPB}$ time (OR, 1.189 per 30 minutes; $P=.035$; $95 \%$ CI, 1.012-1.396) were also associated with postoperative bleeding, in addition to surgery for an infectious cause (OR, $10.824 ; P=.010 ; 95 \%$ CI, 1.755-66.770). Estimated survival at 1,5 , and 7 years was $86.6 \%, 80.5 \%$, and $78.2 \%$, respectively.

Conclusion: Despite the variety of preoperative conditions and operations performed, repeated open surgery for thoracic aorta repair can be performed with acceptable early and late outcomes.

\section{INTRODUCTION}

Sequential operations for aortic pathology are performed in up to $59.6 \%$ of patients with a history of multiple aortic aneurysms in other segments [Crawford 1982]. Moreover, newly developed aneurysm or dissection, infective aortic complications, or valve dysfunction in patients with a history of thoracic aortic repair require reintervention [Di Bartolomeo 2013]. A repeated open repair for sequential

Received March 17, 2017; accepted May 24, 2018.

Correspondence: Kiick Sung, MD, Department of Thoracic and Cardiovascular Surgery, Samsung Medical Center, Sungkyunkwan University School of Medicine, 81 Irwon-ro, Gangnam-gu, Seoul 06351, Korea; +82-2-34106541; fax: +82-2-3410-0089 (e-mail: sungkiick@gmail.com). aortic pathology entails risks that make it challenging from the time of chest reentry. Although endovascular aortic repairs are frequently regarded as viable treatment options in high-risk patients [Stasek 2008], we do not have sufficient information on repeated classic open surgical outcomes for thoracic aortic disease to enable comparison with nonsurgical reinterventions. The aim of this study was (1) to review the characteristics of patients who require sequential and/or repeated operations on the thoracic aorta and (2) to assess the early and long-term clinical results in actual practice.

\section{PATIENTS AND METHODS}

\section{Study Population}

We retrospectively reviewed all patients who underwent any open repair involving the thoracic aorta above the diaphragm after previous surgery on any part of the thoracic aorta. The study excluded patients who previously underwent nonaortic cardiac operations such as coronary artery bypass grafting or heart valve surgery, including isolated aortic valve surgery. Patients who underwent endovascular repair were also excluded. Between 1994 and 2016, 1336 consecutive patients underwent surgery for the thoracic aorta above the diaphragm. Of these, $119(8.9 \%)$ with a history of prior surgery on a thoracic segment before the final operation were analyzed. Patient characteristics, operative variables, reasons for repeated surgery, and perioperative outcomes were evaluated. Survival follow-up was available for all patients. Longterm follow-up was obtained by reviewing medical records. Data for patients followed up by other hospitals were collected by direct telephone interviews with patients or their families. We also confirmed survival from the Republic of Korea National Registry database when survival status was unknown. The Institutional Review Board of Samsung Medical Center approved this retrospective study and waived the need to obtain informed consent (IRB file number: SMC 2017-08-152).

\section{Surgical Techniques and Approach to Operative Field}

Approach to chest reentry was classified into 4 categories according to the previous and present approach: (1) thoracotomy to thoracotomy, (2) thoracotomy to sternotomy, (3) sternotomy to thoracotomy, and (4) sternotomy to sternotomy. When both approaches were used in a previous operation for multiple procedures, the previous approach was taken as the final approach at the last operation, eg, both thoracotomy and sternotomy approaches at a previous operation and the 
Table 1. Patient Demographics and Preoperative Conditions*

\begin{tabular}{|c|c|}
\hline Characteristics & Value \\
\hline Age, $y$, mean \pm SD (range) & $51.0 \pm 16.7(15-83)$ \\
\hline Male, n (\%) & $84(70.6 \%)$ \\
\hline $\mathrm{BSA}, \mathrm{m}^{2}$, mean $\pm \mathrm{SD}($ range $)$ & $1.8 \pm 0.3(1.26-2.64)$ \\
\hline DM, n (\%) & $10(8.4 \%)$ \\
\hline HTN, n (\%) & $65(54.6 \%)$ \\
\hline \multicolumn{2}{|l|}{ Connective tissue disorders or arteritis, $\mathrm{n}(\%)$} \\
\hline Marfan syndrome & $32(26.9 \%)$ \\
\hline Loeys-Dietz syndrome & $6(5.0 \%)$ \\
\hline Behcet disease & $5(4.2 \%)$ \\
\hline None & $76(63.9 \%)$ \\
\hline Emergency operations, $\mathrm{n}(\%)$ & $16(13.4 \%)$ \\
\hline \multicolumn{2}{|l|}{ Number of previous operations } \\
\hline $1, \mathrm{n}(\%)$ & $95(79.8 \%)$ \\
\hline $2, \mathrm{n}(\%)$ & $21(17.6 \%)$ \\
\hline $3, \mathrm{n}(\%)$ & $1(0.8 \%)$ \\
\hline $4, \mathrm{n}(\%)$ & $1(0.8 \%)$ \\
\hline $8, \mathrm{n}(\%)$ & $1(0.8 \%)$ \\
\hline Mean (range) & $1.3 \pm 0.8(1-8)$ \\
\hline \multicolumn{2}{|l|}{ Indications for operation, $\mathrm{n}(\%)$} \\
\hline Aneurysm (remaining or newly developed) & $100(84.0 \%)$ \\
\hline Pseudoaneurysm at the anastomosis site & $10(8.4 \%)$ \\
\hline Infectious conditions & $6(5.0 \%)$ \\
\hline Severe dysfunction of native aortic valve & $3(2.5 \%)$ \\
\hline Interval since last operation, mo, mean $\pm \mathrm{SD}$ (range) & $58.5 \pm 60.2(0-267)$ \\
\hline
\end{tabular}

*BSA, body surface area; DM, diabetes mellitus; HTN, hypertension.

sternotomy approach at the last operation were classified as sternotomy to sternotomy.

Planned sequential repairs were performed with the usual methods (ie, sequential repair for descending thoracic and thoracoabdominal aorta repair via thoracotomy in patients who underwent ascending aortic and arch repair via sternotomy previously, and sequential repair for ascending aorta and aortic arch via sternotomy in patients who underwent repair for descending or thoracoabdominal aorta repair via thoracotomy previously). For descending thoracic or thoracoabdominal aorta repair, we used adjuncts, including distal aortic perfusion, cerebrospinal fluid drainage, motor evoked potential monitoring, and moderate hypothermia. For the ascending aorta, we applied mild hypothermia via median sternotomy. Total arch repair was performed under hypothermic circulatory arrest with selective antegrade cerebral perfusion monitoring and cerebral oximetry. After distal anastomosis, cardiopulmonary bypass $(\mathrm{CPB})$ was reinitiated in an

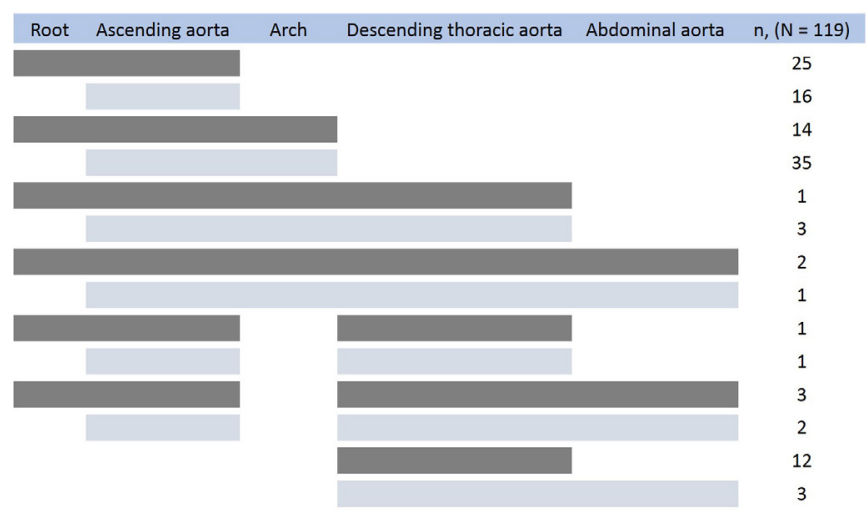

Figure 1. Status of thoracic aorta before the last operation.

antegrade fashion through a branch of the graft. In patients with aortic dissections, arterial cannulation was performed after anastomosis of an 8-mm vascular graft to the axillary artery through a right subclavian incision.

Additional precautions are required in repeated operations on the same aortic segment via the same chest reentry approach because of extensive adhesions. Before chest reopening, $\mathrm{CPB}$ was on standby for all patients. In repeated sternotomy, we established arterial inflow and venous drainage through direct cannulation to the femoral artery and femoral vein, respectively. We limited division of adhesions to those essential for obtaining necessary exposure of the central cannulation site. Once we completed cannulation, the drainage circuit was changed to bicaval or right atrial drainage, and the perfusion catheter was changed, if necessary. In repeated thoracotomy, femoral cannulations of both artery and vein were also applied.

\section{Statistical Analysis}

Categorical variables were presented as frequencies and percentages, and continuous variables as mean and standard deviation. Between-group differences were evaluated using chi-square and Fisher exact tests for categorical variables. Differences in continuous variables among the groups were assessed via independent $t$ test or Mann-Whitney $U$ test, depending on the pertinent distributional assumptions. The distribution of a time-to-event outcome was estimated by using Kaplan-Meier curves. All pre- or intraoperative variables that achieved a $P$ value $<.2$ in univariable analysis were examined by using multivariable analysis by stepwise logistic regression to evaluate independent risk factors for hospital mortality and postoperative bleeding requiring re-exploration. A $P<.05$ was considered statistically significant.

\section{RESULTS}

\section{Baseline Characteristics}

Preoperative demographics and other preoperative conditions are detailed in Table 1. Patients who underwent repeated open surgery had a mean age of $51.0 \pm 16.7$ years, and $70.6 \%$ (84 of 119) were men. A comorbid connective tissue disorder or arteritis was present in $36.1 \%$ of the cohort (43/119). An 
Table 2. Status of Thoracic Aorta before the Last Operation

\begin{tabular}{lc}
\hline Operation name & $\begin{array}{c}\text { Number of } \\
\text { Patients }\end{array}$ \\
\hline
\end{tabular}

Root and/or Ascending aorta
Root and/or Ascending aorta + Arch
Root and/or Ascending aorta + Arch
Root and/or Ascending aorta + Arch
Root and/or Ascending aorta + Desce
Root and/or Ascending aorta + Th
Descending thoracic aorta
Thoracoabdominal aorta
Total
Associated procedures
Aortic valve suspension
Aortic valve replacement
Mitral valve repair
Mitral valve replacement
Tricuspid valve repari
Coronary artery bypass surgery

Table 3. Surgical Procedures

\begin{tabular}{|c|c|}
\hline Operation name & $\begin{array}{c}\text { Number, } \mathrm{n} \\
\text { or } \mathrm{n}(\%)\end{array}$ \\
\hline \multicolumn{2}{|l|}{ Ascending aorta involving root surgery } \\
\hline Bentall & $10(8.4 \%)$ \\
\hline Valve-sparing aortic root replacement & $2(1.7 \%)$ \\
\hline \multicolumn{2}{|l|}{ Ascending aorta surgery (Alone) } \\
\hline Ascending aorta replacement & $2(1.7 \%)$ \\
\hline Ascending aorta repair & $2(1.7 \%)$ \\
\hline \multicolumn{2}{|l|}{ Arch surgery } \\
\hline Ascending aorta replacement + Hemiarch replacement & $2(1.7 \%)$ \\
\hline Ascending aorta replacement + Total arch replacement & $14(11.8 \%)$ \\
\hline \multicolumn{2}{|l|}{ Root + Ascending aorta + Arch surgery } \\
\hline Bentall + Total arch replacement & $2(1.7 \%)$ \\
\hline Valve-sparing aortic root replacement + Total arch replacement & $5(4.2 \%)$ \\
\hline \multicolumn{2}{|l|}{ Arch + Descending thoracic aorta surgery } \\
\hline Partial arch replacement + Descending thoracic aorta replacement & $1(0.8 \%)$ \\
\hline Total arch replacement + Descending aorta replacement & $2(1.7 \%)$ \\
\hline \multicolumn{2}{|l|}{ Arch + Thoracoabdominal aorta surgery } \\
\hline Partial arch replacement + Thoracoabdominal aorta replacement & $1(0.8 \%)$ \\
\hline Total arch replacement + Thoracoabdominal aorta replacement & $4(3.4 \%)$ \\
\hline \multicolumn{2}{|l|}{ Descending thoracic aorta surgery (Alone) } \\
\hline Descending thoracic aorta replacement & $29(24.4 \%)$ \\
\hline \multicolumn{2}{|l|}{ Thoracoabdominal aorta surgery } \\
\hline Thoracoabdominal aorta replacement & $41(34.5 \%)$ \\
\hline \multicolumn{2}{|l|}{ Others } \\
\hline Arch to Descending aorta bypass & $1(0.8 \%)$ \\
\hline Ascending aorta to abdominal aorta bypass & $1(0.8 \%)$ \\
\hline \multicolumn{2}{|l|}{ Associated procedures } \\
\hline Aortic valve suspension & 6 \\
\hline Aortic valve replacement & 2 \\
\hline Mitral valve repair & 2 \\
\hline Tricuspid repair & 1 \\
\hline$C A B G *$ & 5 \\
\hline Common carotid artery bypass & 1 \\
\hline
\end{tabular}

*CABG, Coronary artery bypass grafting.

30 minutes; $P=.007 ; 95 \%$ CI, 1.126-2.165) were predictors of hospital death in 30 days. Exploration for bleeding (in situations in which bleeding needed exploration) occurred in 19 $(16 \%)$ and was associated with operation for infectious cause (OR, 10.824; $P=.010 ; 95 \%$ CI, 1.755-66.770), emergency operation (OR, 4.105; $P=.029 ; 95 \% \mathrm{CI}, 1.157-14.567)$, and $\mathrm{CPB}$ time (OR, 1.189 per 30 minutes; $P=.035 ; 95 \% \mathrm{CI}$, 1.012-1.396) (Table 4). 
Table 4. Predictors of Perioperative Outcomes*

\begin{tabular}{|c|c|c|c|c|c|c|c|c|}
\hline & OR $(95 \% \mathrm{Cl})$ & $P$ & OR $(95 \% \mathrm{Cl})$ & $P$ & $\operatorname{HR}(95 \% \mathrm{Cl})$ & $P$ & $\operatorname{HR}(95 \% \mathrm{Cl})$ & $P$ \\
\hline Age & $1.047(0.994-1.103)$ & .085 & $1.044(0.977-1.115)$ & .203 & $1.003(0.974-1.033)$ & .829 & & \\
\hline Sex (female) & $0.388(0.091-1.646)$ & .199 & $0.236(0.029-1.918)$ & .177 & $0.885(0.307-2.553)$ & .821 & & \\
\hline DM & $4.292(0.742-24.809)$ & .104 & $2.689(0.229-31.620)$ & .432 & $1.353(0.264-6.930)$ & .717 & & \\
\hline HTN & $2.644(0.511-13.674)$ & .246 & & & $1.717(0.434-3.159)$ & .755 & & \\
\hline BSA & $0.198(0.008-4.801)$ & .319 & & & $0.439(0.058-3.345)$ & .427 & & \\
\hline Number pOP & $0.558(0.080-3.880)$ & .555 & & & $0.972(0.507-1.864)$ & .932 & & \\
\hline Infectious cause & $3.029(0.310-29.586)$ & .341 & & & $13.067(2.199-77.657)$ & .005 & $10.824(1.755-66.770)$ & .010 \\
\hline
\end{tabular}

*HR, hazard ratio; CTD, connective tissue disorder; DM, diabetes mellitus; HTN, hypertension; BSA, body surface area; Number pOP, number of previous operations; CPB, cardiopulmonary bypass.

Mean hospital stay was $28.1 \pm 49.5$ days, and mean intensive care unit stay was $6.3 \pm 12.0$ days. Other postoperative complications were hospital-acquired pneumonia in $11(9.2 \%)$, acute renal failure requiring temporary dialysis in $11(9.2 \%)$, gastrointestinal bleeding from bowel ischemia in $5(4.2 \%)$, wound dehiscence in $4(3.4 \%)$, chylothorax in $2(1.7 \%)$, esophageal perforation in $2(1.7 \%)$, vocal cord palsy in $5(4.2 \%)$, cerebral complications in $10(84 \%)$, and paraplegia in $2(1.7 \%)$.

\section{Long-term Results}

Mean follow-up period was $44 \pm 47.1$ months. The KaplanMeier estimate of overall survival at 1, 3, 5, and 7 years was $86.6 \%, 84 \%, 80.5 \%$, and $78.2 \%$, respectively (Figure 2). Of 111 discharged survivors, 13 (11.7\%) died during follow-up. Causes of death were cerebrovascular accident in 5, aortic rupture in 2, community-acquired pneumonia in 2, cancer in 2 , sepsis in 1, and unknown cause in 1. During follow-up, 2 patients had progressive heart failure and, 1 needed surgery for an incisional hernia.

\section{DISCUSSION}

Aortic operations have been performed with increasing frequency during the last decade, with a significant improvement in outcomes. In patients who undergo initial thoracic aorta repair, progression of an aneurysm in the previously repaired segment or newly developed disease in another segment are not uncommon. Aneurysm at the previous anastomotic suture site and infection of the graft implanted in a previous operation have been reported [Bickerstaff 1982; Crawford 1982; Carrel 1993; Svensson 1993; Etz 2009]. Furthermore, in patients with connective tissue disease such as Marfan syndrome, characterized by frequent aortic aneurysms involving the entire aorta, repair cannot be completed at the first operation. These patients require sequential operations. As a result, reintervention for the thoracic aorta is inevitable and has become common [Di Bartolomeo 2013]. Owing to technical difficulties and risks, repeated and/or additional interventions for the thoracic aorta require a well-defined strategic approach in order to be successful. Since the advent of alternative repair methods, including endovascular repair or hybrid surgery for aortic disease, many centers have justified the use of these treatments for patients at high risk [Muhs 2006; Roselli 2007; Johnston 2012; Rosset 2014; Verhoeven 2015; Gallitto 2016; Mendes 2016; Georgiadis 2017]. To identify the best strategy among these various options, we need to perform combined assessment of the preprocedural conditions, risks of the procedures, and benefits from the procedures. For this purpose, the outcomes of repeated classic open surgery for the thoracic aorta should be evaluated as they apply to real-world practice. Data are available on outcomes of repeated aortic procedures in individual segments. In previous literature, hospital mortality rates for redo operations on the proximal aorta including the arch and on the thoracoabdominal aorta were $8 \%-15 \%$ and $8 \%-23 \%$, respectively [Chiesa 2014; Preventza 2014; Afifi 2017; Di Bartolomeo 2017; Coselli 2018]. However, aortic disease is lifelong and progressive and may require repeated or additional intervention on different segments over time. Aortic disease progression varies widely, resulting in various indications and treatment options in actual practice. Furthermore, previous literature included cases that underwent preceding nonsurgical interventions and interventions on the abdominal aorta. Before determining the superiority of one method over another, we need to confirm the overall outcomes of conventional repeated operations on the thoracic aorta as a reference for comparison with other treatment options. In the present study, early overall outcomes of thoracic aortic reoperations 


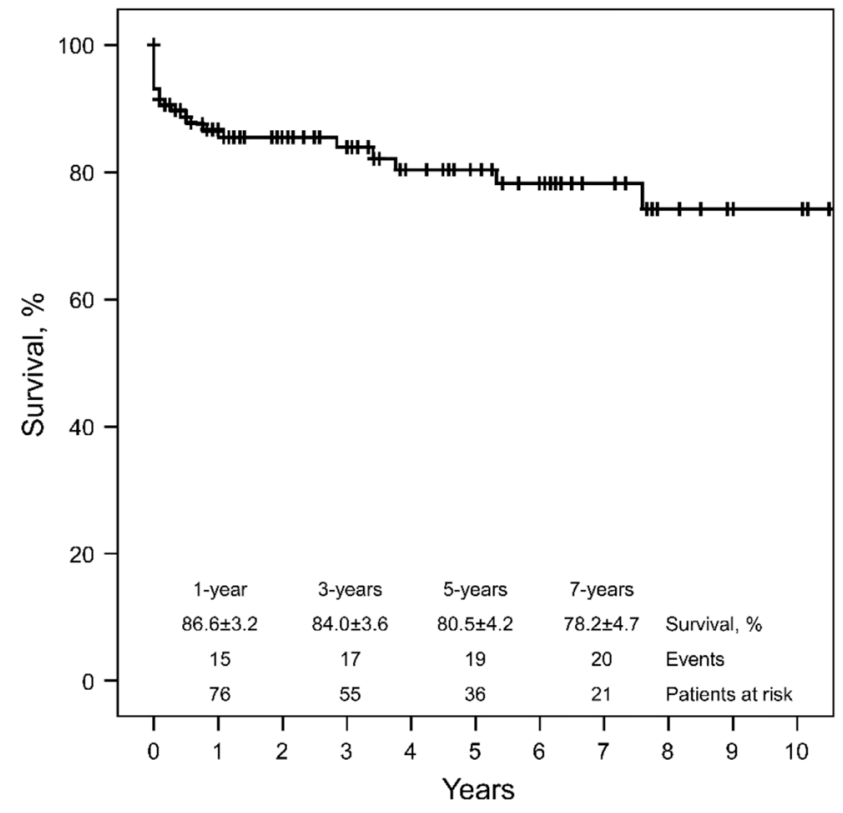

Figure 2. Overall Kaplan-Meier estimate of survival.

appear to be similar to those for other repeated operations focused on the proximal or thoracoabdominal aorta [Preventza 2014; Quintana 2014; Coselli 2018]. Hospital mortality in our cohort was $6.7 \%$ overall. Hospital mortality increased as $\mathrm{CPB}$ time increased. This result is also concordant with a recent report by Di Bartolomeo et al, in which CPB time emerged as the only independent predictor of hospital death after open arch repair following a prior aortic operation [Di Bartolomeo 2017]. Moreover, in a study by Quintana et al on 168 patients who underwent arch reconstruction after cardiac surgery, CPB time was one of the predictors of perioperative death [Quintana 2014]. Prolonged CPB may reflect the complexity of the operation and may lead to a poor outcome. Of course, prolonged CPB itself might lead to an adverse outcome. Prolonged CPB time was also attributed to postoperative bleeding in our study. A major concern in repeated open surgery for the thoracic aorta is bleeding from extensive lysis of adhesions. Multivariable analysis for postoperative bleeding that required exploration identified 3 significant variables (infectious cause, emergency operation, and CPB time). Infection might require extensive dissection to secure the operative field during adhesiolysis of especially friable tissue. After discharge, estimated survival was $80.5 \%$ at 5 years and $78.2 \%$ at 7 years (Figure 2), similar or slightly superior to previous reports [Chong 2016; Afifi 2017; Di Bartolomeo 2017; Coselli 2018]. Considering the heterogeneity of previous aortic repair status and surgical procedures performed in our study, it is interesting to note similar overall surgical outcomes for thoracic aortic reoperations.

\section{Limitations}

In addition to its retrospective nature, our study has other limitations. The patients were heterogeneous, with differences in the types of previous operation, indications for reoperation, approach to the surgical field, and concomitant procedures performed. However, the effect of heterogeneity of repeated surgery on overall thoracic aortic pathology was the motivation for our study. Our experience in actual practice served as the reference for the overall outcome of surgical retreatment in patients with thoracic aortic disease.

\section{CONCLUSION}

Despite the above limitations, our study reported practical results in patients treated in actual clinical settings. Although previous procedures on the thoracic aorta varied, the overall early and late outcomes were acceptable. We hope that our study findings will serve as a reference for selection of appropriate procedures in patients who require repeated intervention on the thoracic aorta.

\section{REFERENCES}

Afifi RO, Sandhu HK, Trott AE, et al. 2017. Redo thoracoabdominal aortic aneurysm repair: a single-center experience over 25 years. Ann Thorac Surg 103:1421-28.

Bickerstaff LK, Pairolero PC, Hollier LH, et al. 1982. Thoracic aortic aneurysms: a population-based study. Surgery 92:1103-8.

Carrel T, Pasic M, Jenni R, Tkebuchava T, Turina MI. 1993. Reoperations after operation on the thoracic aorta: etiology, surgical techniques, and prevention. Ann Thorac Surg 56:259-68; discussion 269.

Chiesa R, Bertoglio L, Kahlberg A, Rinaldi E, Tshomba Y, Melissano G. 2014. Redo surgery in ascending aorta and aortic arch. J Cardiovasc Surg (Torino) 55:803-12.

Chong BK, Jung SH, Choo SJ, Chung CH, Lee JW, Kim JB. 2016. Reoperative aortic root replacement in patients with previous aortic root or aortic valve procedures. Korean J Thorac Cardiovasc Surg 49:250-7.

Coselli JS, Rosu C, Amarasekara HS, et al. 2018. Reoperative surgery on the thoracoabdominal aorta. J Thorac Cardiovasc Surg 155:474-85.e1.

Crawford ES, Cohen ES. 1982. Aortic aneurysm: a multifocal disease: Presidential address. Arch Surg 117:1393-400.

Di Bartolomeo R, Berretta P, Pantaleo A, et al. 2017. Long-term outcomes of open arch repair after a prior aortic operation: our experience in 154 patients. Ann Thorac Surg 103:1406-12.

Di Bartolomeo R, Berretta P, Petridis FD, et al. 2013. Reoperative surgery on the thoracic aorta. J Thorac Cardiovasc Surg 145:S78-84.

Etz CD, Zoli S, Kari FA, et al. 2009. Redo lateral thoracotomy for reoperative descending and thoracoabdominal aortic repair: a consecutive series of 60 patients. Ann Thorac Surg 88:758-66; discussion 767.

Gallitto E, Gargiulo M, Freyrie A, et al. 2016. Fenestrated and branched endograft after previous aortic repair. Ann Vasc Surg 32:119-27.

Georgiadis GS, van Herwaarden JA, Saengprakai W, et al. 2017. Endovascular treatment of complex abdominal and thoracoabdominal type IV aortic aneurysms with fenestrated technology. J Cardiovasc Surg (Torino) 58:574-90.

Johnston WF, Upchurch GR Jr, Tracci MC, Cherry KJ, Ailawadi G, Kern JA. 2012. Staged hybrid approach using proximal thoracic endovascular aneurysm repair and distal open repair for the treatment of extensive thoracoabdominal aortic aneurysms. J Vasc Surg 56:1495-502. 
Mendes BC, Oderich GS. 2016. Endovascular repair of thoracoabdominal aortic aneurysm using the off-the-shelf multibranched t-Branch stent graft. J Vasc Surg 63:1394-99.e2.

Muhs BE, Verhoeven EL, Zeebregts CJ, et al. 2006. Mid-term results of endovascular aneurysm repair with branched and fenestrated endografts. J Vasc Surg 44:9-15.

Preventza O, Garcia A, Cooley DA, et al. 2014. Reoperations on the total aortic arch in 119 patients: short- and mid-term outcomes, focusing on composite adverse outcomes and survival analysis. J Thorac Cardiovasc Surg 148:2967-72.

Quintana E, Bajona P, Schaff HV, et al. 2014. Open aortic arch reconstruction after previous cardiac surgery: outcomes of 168 consecutive operations. J Thorac Cardiovasc Surg 148:2944-50.

Roselli EE, Greenberg RK, Pfaff K, Francis C, Svensson LG, Lytle BW. 2007. Endovascular treatment of thoracoabdominal aortic aneurysms. J
Thorac Cardiovasc Surg 133:1474-82.

Rosset E, Ben Ahmed S, Galvaing G, et al. 2014. Editor's choice hybrid treatment of thoracic, thoracoabdominal, and abdominal aortic aneurysms: a multicenter retrospective study. Eur J Vasc Endovasc Surg 47:470-8.

Stasek J, Polansky P, Bis J, et al. 2008. The percutaneous closure of a large pseudoaneurysm of the ascending aorta with an atrial septal defect Amplatzer occluder: two-year follow-up. Can J Cardiol 24:e99-101.

Svensson LG, Crawford ES, Hess KR, Coselli JS, Safi HJ. 1993. Experience with 1509 patients undergoing thoracoabdominal aortic operations. J Vasc Surg 17:357-68; discussion 368-70.

Verhoeven EL, Katsargyris A, Bekkema F, et al. 2015. Editor's Choice ten-year experience with endovascular repair of thoracoabdominal aortic aneurysms: results from 166 consecutive patients. Eur J Vasc Endovasc Surg 49:524-31. 